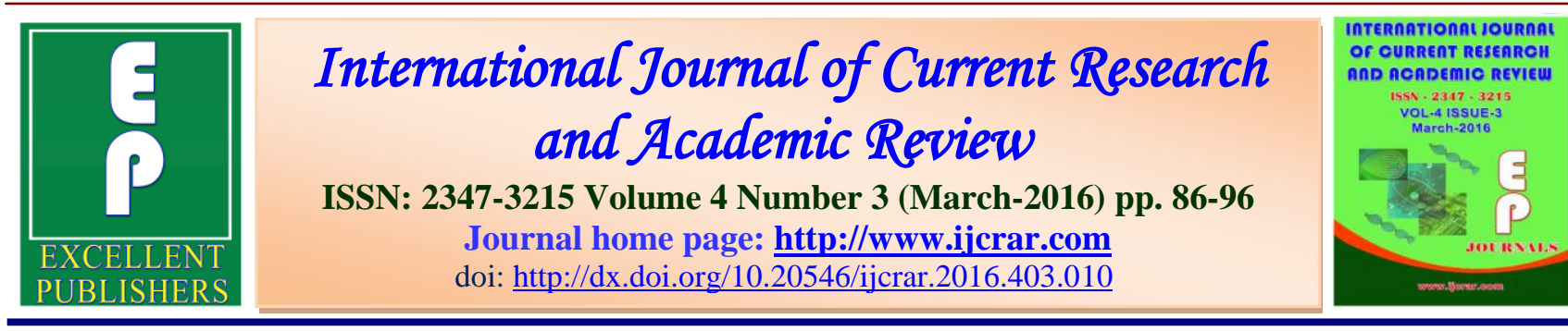

\title{
Proliferatic Potential of Hematopoietic Stem Cells (HSC) and its Application in Human Diseases
}

\author{
Pallavi Singh ${ }^{1 *}$, Naman Naik ${ }^{2}$ and Lakhan L. Naik ${ }^{3}$ \\ ${ }^{1}$ Matrikripa, G-39, Near Manju Kumari Sinha Smriti Park, P.C. Colony, Kankarbagh, Patna - \\ 800020, Bihar, India \\ ${ }^{2}$ Lotus 404, Welfare Diah Height, Chiragora, Dhanbad- 826001, Jharkhand, India M.Tech- \\ Animal Biotechnology (Final Year), Sharda University, India \\ ${ }^{3}$ Lotus 404, Welfare Diah Height, Chiragora, Dhanbad- 826001, Jharkhand, India
}

*Corresponding author

\begin{tabular}{|l|l|}
\hline \multirow{2}{*}{$\begin{array}{l}\text { KEYWORDS } \\
\text { Cells (HSC), }\end{array}$} & A B S T R A C T \\
\cline { 2 - 2 } $\begin{array}{l}\text { Proliferatic potential, } \\
\text { Plasticity, Progenitor } \\
\text { cells, Cell lineage, }\end{array}$ & $\begin{array}{l}\text { Plasticity is a newly recognized ability of stem cells to express their potential } \\
\text { beyond the tissues from which they are derived. Organ generations have long } \\
\text { been believed to be undertaken through organ specific and tissue specific } \\
\text { stem cells. HSC's(Hematopoietic Stem Cells) are involved in replenishing } \\
\text { apoptic and damaged cells. Currently, using Cell Lineage tracking stem cells } \\
\text { of another organ by supplementing appropriate cytokines and growth factors } \\
\text { that provide signal for differentiating into desired organ. As suggested by } \\
\text { McCulloch(1963), during development and proliferation of HSC interaction } \\
\text { of C Kit (as a ligand) with its receptor on stromal cells, in bone marrow, a } \\
\text { hierarchy of stem cells and progenitor cells differentiate and produce different } \\
\text { sub lineage of cells. Further, most important information need to be elicited, } \\
\text { is to decode common molecular mechanism and genes involved in initiating } \\
\text { stem cell taking lead in differentiation to a specific organ. Neurodegenerative } \\
\text { cells in certain neuron related diseases may be advantageously generated } \\
\text { through this technology. }\end{array}$
\end{tabular}

\section{Introduction}

Stem Cells, also called biological cells, are found in all multicellular organisms, which can divide (via mitosis) and differentiate into diverse specialized cell types and can self-renew to produce more stem cells. In mammals, there are two broad types of stem cells: embryonic stem cells, which are isolated from the inner cell mass of blastocysts, and adult stem cells, which are found in various tissues. In adult organisms, stem cells and progenitor cells act as a repair system for the body, replenishing adult tissues. Although in a developing embryo, stem cells can differentiate into all the 
specialized cells (called pluripotent cells), yet they also maintain the normal turnover of regenerative organs, such as blood, skin, or intestinal tissues. The classical definition of a stem cell requires that it possess two properties, viz.

Self-renewal: The ability to go through numerous of cell divisions while maintaining the undifferentiated state.

Potency: The capacity to differentiate into specialized cell types. In the strictest sense, this requires stem cells to be either unipotent or pluripotent, so as to be able to give rise to any mature cell type, although multipotent or unipotent progenitor cells are sometimes referred to as 'stem cells'. Apart from this, it is said that stem cell function is regulated in a feedback mechanism.

\section{Self-renewal}

There are two known mechanisms to ensure that a stem cell population is maintained. These are:

Obligatory asymmetric replication: A stem cell divides into one 'Father Cell' that is identical to the original stem cell, and another 'Daughter cell that is differentiated.

Stochastic differentiation: When one stem cell develops into two differentiated daughter cells, another stem cell undergoes mitosis and produces two stem cells identical to the original.

\section{Potency}

Potency specifies the differentiation potential (the potential to differentiate into different cell types) of the stem cell.

Totipotent (omnipotent) stem cells can differentiate into embryonic and extra embryonic and extra embryonic cell types. Such cells can construct a complete, viable organism. These cells are produced from the fusion of an egg and sperm cell. Cells produced by the first few divisions of the fertilized egg are also totipotent.

Pluripotent stem cells are the descendants to totipotent cells and can differentiate into nearly all cells, i.e. cells derived from any of the three germ layers.

Multipotent stem cells can differentiate into a number of cells, as for only those of a closely related family of cells.

Oligopotent stem cells can differentiate into only a few cells, such as lymphoid or myeloid stem cells.

Unipotent cells can produce only one cell type - their own, but have the property of self-renewal, which distinguishes them from non-stem cells (e.g., muscle stem cells).

Stem cell systems, thus, represent an effective and powerful approach for tissue development and regeneration of diverse tissue types. Common and defining features of these exceptional cells are the capacity for self-renewal and the potential for differentiation into multiple mature cell types. Recently, some new, surprising observations have indicated that stem cells isolated from one adult tissue can also give rise to mature cells of other cell lineages, irrespective of classical germ layer designations. This finding has taken quantum jump in both scientific knowledge and the potential applications of stem cells. Thus, the new findings contradict central dogmas of commitment and differentiation of stem and progenitor cells. Not withstanding this, the true potential of somatic stem cells is just emerging and accordingly the new findings have to be 
defined more fully and integrated into a unifying model of stem cell potential and behavior. As such, the emerging lines of evidence of the developmental plasticity of hematopoietic and other somatic stem cells can be potentially involved in treating many human diseases.

With more than 50 years of experience of studying blood-forming stem cells - called hematopoietic stem cells, scientists have developed sufficient understanding to actually use them as a therapy. Currently, no other type of stem cell - adult, fetal or embryonic, has attained such status. Hematopoietic stem cells (HSCs) are the blood cells that give rise to all other blood cells and are derived from mesoderm. They are located in the red bone marrow, which are contained in the core of most bones. They give rise to the myeloid (monocytes and macrophages, neutrophils, basophils, eosinophils, erythrocytes, megakaryocytes/platelets, dendritic cells), and lymphoid lineages (T-cells, B-cells, NK cells). Hematopoietic stem cell transplants are now being routinely used to treat patients with cancers and other disorders of the blood and immune systems. Recently, researchers have observed in animal studies that hematopoietic stem cells appear to be able to form other kinds of cells, such as muscle, blood vessels, and bone. If this can be applied to human cells, it may eventually be possible to use hematopoietic stem cells to replace a wider array of cells and tissues than once was believed not possible.

Despite the vast experience with hematopoietic stem cells, scientists are still facing major roadblocks in expanding their use beyond the replacement of blood and immune cells. First, hematopoietic stem cells are unable to proliferate (replicate themselves) and differentiate (become specialized to other cell types) in vitro (in the test tube or culture dish). Second, scientists do not yet have an accurate method to distinguish stem cells from other cells recovered from the blood or bone marrow. Therefore, it will be only prudent that until scientists overcome these technical barriers, it would be unlikely that hematopoietic stem cells will be applied as cell replacement therapy in diseases such as Diabetes, Parkinson's Disease, spinal cord injury, and many others. Since blood cells are responsible for constant maintenance and immune protection of every cell type of the body, their relentless and brutal work requires that blood cells, along with skin cells, must have the greatest powers of selfrenewal of any adult tissue.

Blood and immune cell forming stem cells are known as hematopoietic stem cells (HSCs) and they are ultimately responsible for the constant renewal of blood which is responsible for the production of billions of new blood cells each day. Physicians and basic researchers have known and capitalized on this fact for more than 50 years in treating many diseases. The first evidence and definition of blood-forming stem cells came from studies of people exposed to lethal doses of radiation in 1945. Taking a cue from this, basic research soon followed. After duplicating radiation sickness in mice, scientists found they could rescue the mice from death with bone marrow transplants from healthy donor animals. In the early 1960s, Till and McCulloch began analyzing the bone marrow to find out which components were responsible for regenerating blood. They defined what the two hallmarks of an HSC remain: it can renew itself, and it can produce cells that give rise to all the different types of blood cells. This is shown in Fig I which depicts the sources of HSCs.

Sources of Hematopoietic Stem Cells 
1. Bone Marrow

2. Peripheral Blood

3. Umbilical Cord Blood

4. Fetal Hematopoietic System

5. Embryonic Stem Cells and Embryonic Germ Cells

HSC in the bone marrow has four actions in its repertoire: 1) it can renew itself, 2) it can differentiate, 3) it can mobilize out of the bone marrow into circulation (or the reverse), or 4) it can undergo programmed cell death, or apoptosis. Understanding the how, when, where, which, and why of this simple repertoire will allow researchers to manipulate and use for tissue and organ repair is still not very clear and in-depth research on this aspect needs to be carried out.

Clinical Uses of Hematopoietic Stem Cells using cord blood stem cells are described in Table-1 below:

Table.1 Depicts the Diseases that can be Cured by Haematopoietic Stem Cells

\begin{tabular}{|l|}
\hline $\begin{array}{l}\text { Myelodysplastic Syndromes are also called pre-leukemia Leukemia is a cancer of the blood immune system, where } \\
\text { the cells are called leukocytes or white }\end{array}$ \\
\hline 1. Acute Lymphoblastic Leukemia (ALL) \\
\hline 2. Acute Myelogenous Leukemia (AML) \\
\hline 3. Acute Biphenotypic Leukemia \\
\hline 4. Acute Undifferentiated Leukemia \\
\hline 5. Chronic Lymphocytic Leukemia (CLL) \\
\hline 6. Chronic Myelogenous Leukemia (CML) \\
\hline 7. Juvenile Chronic Myelogenous Leukemia (JCML) \\
\hline 8. Juvenile Myelomonocytic Leukemia (JMML) \\
\hline \\
\hline 1. Refractory Anemia \\
\hline 2. Refractory Anemia with Ringed Sideroblasts \\
\hline 3. Refractory Anemia with Excess Blasts \\
\hline 4. Refractory Anemia with Excess Blasts in Transformation \\
\hline 5. Chronic Myelomonocytic Leukemia \\
\hline Lymphoma is a cancer of the leukocytes that circulate in the blood and lymph vessels \\
\hline 1. Hodgkin's Lymphoma \\
\hline 2. Non-Hodgkin's Lymphoma \\
\hline \\
\hline Other Disorders of Blood Cell Proliferation \\
\hline 1. Anemias \\
\hline 2. Aplastic Anemia \\
\hline 3. Fanconi Anemia \\
\hline 4. Congenital Dyserythropoietic Anemia \\
\hline 5. Paroxysmal Nocturnal Hemoglobinuria \\
\hline 6. Inherited Red Cell Abnormalities \\
\hline 7. Sickle Cell Disease \\
\hline 8. Beta Thalassemia Major \\
\hline 9. Diamond-Blackfan Anemia \\
\hline 10. Pure Red Cell Aplasia \\
\hline 11. Inherited Platelet Abnormalities \\
\hline 12. Amegakaryocytosis / Congenital Thrombocytopenia \\
\hline 13. Glanzmann Thrombasthenia \\
\hline
\end{tabular}


Int.J.Curr.Res.Aca.Rev.2016; 4(3): 86-96

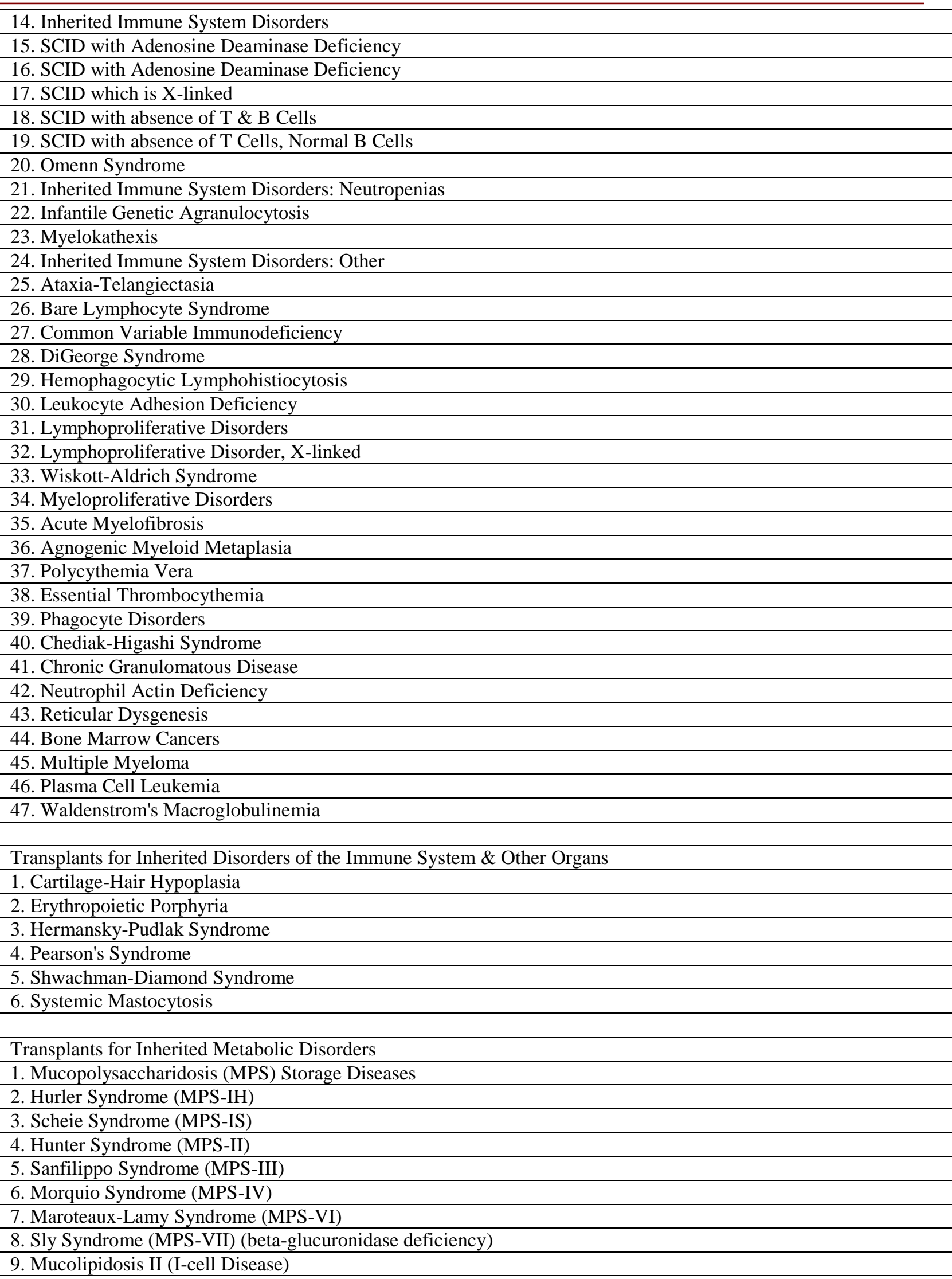


Int.J.Curr.Res.Aca.Rev.2016; 4(3): 86-96

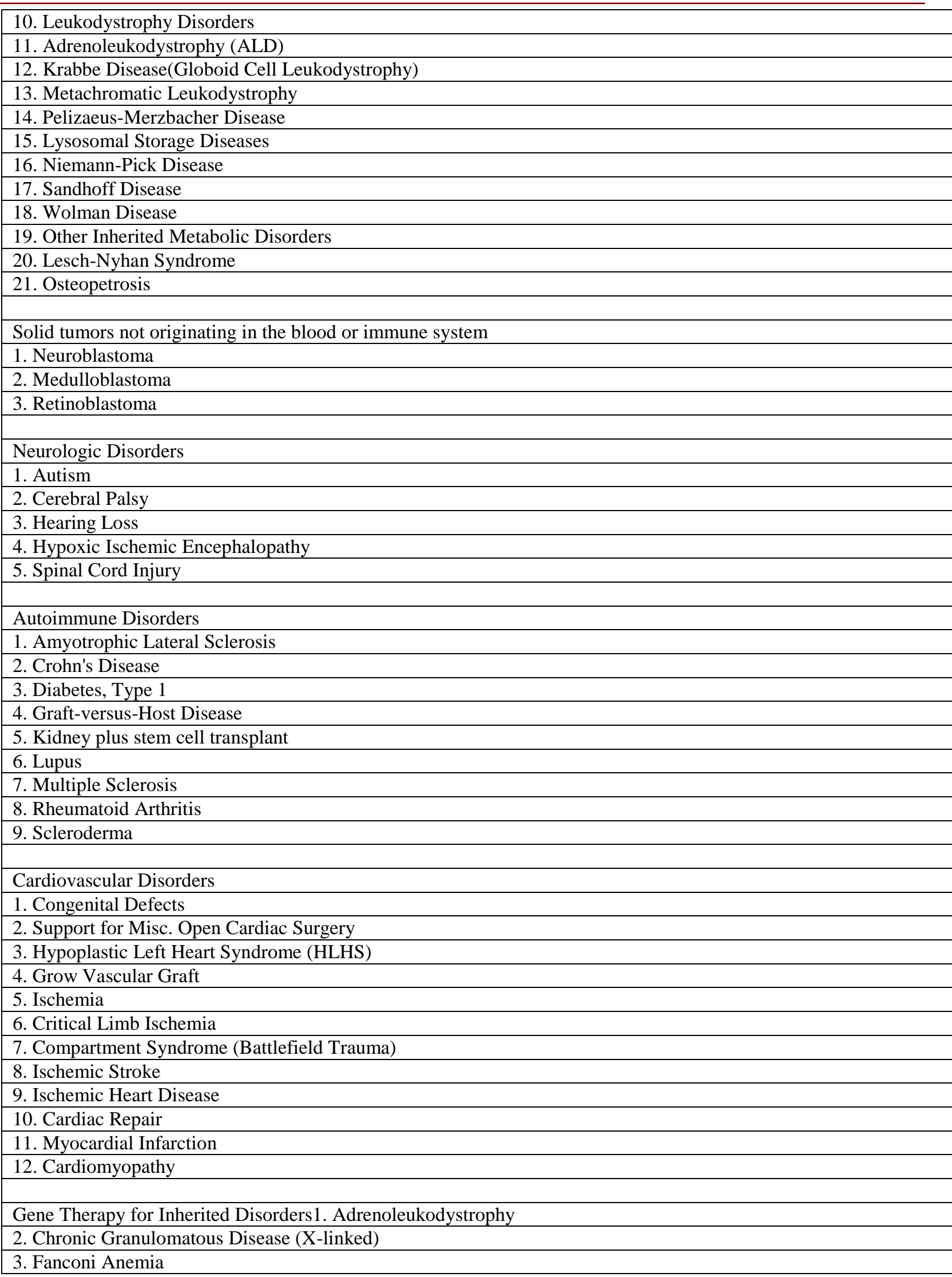


Int.J.Curr.Res.Aca.Rev.2016; 4(3): 86-96

\begin{tabular}{|l|}
\hline 4. HIV \\
\hline 5. Metachromatic Leukodystrophy \\
\hline 6. Severe Combined Immunodeficiency \\
\hline 7. Sickle Cell \\
\hline 8. Thalassemia \\
\hline 9. Wiskott-Aldrich Syndrome \\
\hline \\
\hline Orthopadaeic disorders \\
\hline 1. Alveolar Cleft Palate Repair \\
\hline 2. Knee Cartilage Repair \\
\hline Miscellaneous \\
\hline 1. Bronchopulmonary Dysplasia (BPD) \\
\hline 2. Epidermolysis Bullosa \\
\hline 3. HIV aka "AIDS" \\
\hline 4. Lysosomal Storage Diseases \\
\hline \\
\hline Source: Parents guide to cord blood \\
\hline Treatments using cord tissue stem cells \\
\hline Over 30 clinical trials around the world are researching the capability of these stem cells in treating: \\
\hline 1. Stroke \\
\hline 2. Spinal cord injury \\
\hline 3. Liver disease \\
\hline 4. Diabetes \\
\hline 5. Cartilage injury \\
\hline
\end{tabular}

Fig.1 Sources of Haematopoietic Stem Cells

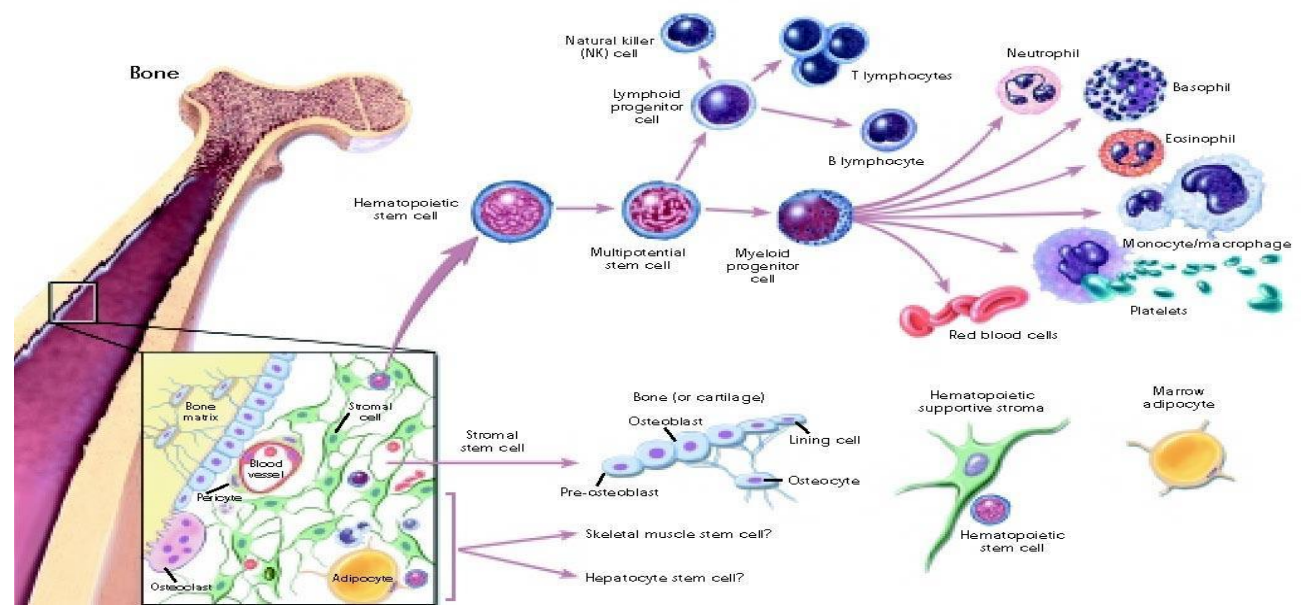

\section{The Stem Cell Database}

IhorLemishka and colleagues at Princeton University and the Computational Biology and Informatics Laboratory at the University of Pennsylvania have collaborated to record all the findings about hematopoietic stem cells (HSC) genes and markers in the Stem Cell Database.

These collaborators have diligently prepared the database five years ago, its goal being listing and annotating all the genes that are differentially expressed in mouse liver HSCs from different blood sources, and a related 
database, constructed in collaboration with Kateri A. Moore - also at Princeton University. Based on this data bank it will be possible to document all genes active in stromal cells, which provide the microenvironment in which stem cells are maintained. The combined power of the two databases, along with new tools and methods for studying molecular biology, will help researchers put together a complete portrait of the hematopoietic stem cell and how it works. Further, these databases will continue to grow and take advantage of other efforts, such as those to complete the gene sequences of mammals. So as to take gainful advantage of these data banks, they are proposed to be publicly available to researchers around the world to carry forward further researches to fill the existing void in the research already done till now.

\section{The National Marrow Donor Program}

Launched in 1987, the National Marrow Donor Program (NMDP) was created to connect patients who need blood-forming stem cells or bone marrow with potential nonrelated donors. Ironically, about 70 percent of patients who need a life-saving HSC transplant cannot find a match in their own family.

The NMDP is made up of an international network of centres and banks that collect cord blood, bone marrow, and peripherally harvested stem cells and that recruit potential donors. As of February 28, 2001, NMDP listed 4,291,434 potential donors. Since its start, the Minneapolis-based group has facilitated almost 12,000 transplants-75 percent of them for leukemia. As per the recent data, the total no of more than 1 million blood stem cell transplants has been made upto 11.3.2015 in USA. In India too, although successful stem cell transplants are being made, the data for exact number of transplants made is not available.

\section{Barriers to the Development of New and Improved Treatments Using Hematopoietic Stem Cells}

Notwithstanding the advances made till now in stem cell research, there are many barriers in the development of new and improvised treatment methods and skills using HSCs. They are mentioned below:

Boosting the Numbers of Hematopoietic Stem Cells

Outfoxing the Immune System in Host, Graft, and Pathogen Attacks

Understanding the Differentiating Environment and Developmental Plasticity

\section{Research 30 November, 2015}

The growth factor independence-1( GFI1) proteins orchestrate the emergence of haematopoietic stem cells through recruitment of Lysine specific demethylase1 (LSD1)

\section{Research | 16 November 2015}

A perisinusoidal niche for extramedullary haematopoiesis in the spleen

Haematopoietic stem cells normally reside in a bone marrow niche but they are recruited to the spleen after physiological stresses; here, endothelial cells and stromal cells around sinusoidal blood vessels of the spleen are shown to secrete key niche factors to support this process

\section{Reviews | 07 December 2015}

Childhood to adult transition and long-term follow-up after blood and marrow transplantation 


\section{Research | 02 December 2015 |}

Amelioration of murine sickle cell disease by nonablative conditioning and $\gamma$-globin gene-corrected bone marrow cells

\section{Conclusion}

Grounded in half a century of research, the study of hematopoietic stem cells is one of the most exciting and rapidly advancing disciplines in biomedicine today. Breakthrough discoveries in both the laboratory and clinic have sharply expanded the use and supply of life-saving stem cells. Yet; even more promising applications are on the horizon and scientist's current inability to grow HSCs outside the body could delay or thwart progress with these new therapies.

New treatments include graft-versus-tumors therapy for currently incurable cancers, autologous transplants for autoimmune diseases, and gene therapy and tissue repair for a host to other problems. The techniques, cells, and knowledge that researchers have now are found to be inadequate to realize the full promise of HSC-based therapy.

Thus, in conclusion, some key issues for tapping the potential of hematopoietic stem cells will be finding ways to safely and efficiently expand the numbers of transplantable human HSCs in vitro or in vivo. Moreover, it will also be important to gain a better understanding of the fundamentals of how immune cells work in fighting infections, in causing transplant rejection, and in graft-versus-host disease as well as master the basics of HSC differentiation. Concomitant advances in the gene therapy techniques and the understanding of cellular plasticity are also likely to make HSCs one of the most powerful tools for healing.

\section{References}

1. Alison, M.R., et al. 2000. Hepatocytes from non-hepatic adult stem cells. Nature, 406: 257.

2. Audet, J., et al. 2001. Distinct role of gp130 activation in promoting selfrenewal divisions by mitogenically stimulated murine hematopoietic stem cells. Proc. Natl. Acad. Sci. U.S.A., 98: 1757-1762.

3. Baum, C.M., et al. 1992. Isolation of a candidate human hematopoietic stem cell population. Proc. Natl. Acad. Sci. U.S.A., 89: 2804-2808.

4. Bertrand, J.Y., et al. 2010. Haematopoietic stem cells derive directly from aortic endothelium during development. Nature, 464: 108-111.

5. Bittner, R.E., et al. 1999. Recruitment of bone-marrow-derived cells by skeletal and cardiac muscle in adult dystrophic mdx mice. Anat. Embryol. (Berl)., 199: 391-396.

6. Boisset, J.C., et al.2010. In vivo imaging of haematopoietic cells emerging from the mouse aortic endothelium. Nature, 464: 116-120.

7. Boisset, J.C., et al. 2015. Progressive maturation toward hematopoietic stem cells in the mouse embryo aorta. Blood, 125: 465-469.

8. Chen, J., et al. 1999. Development and ageing of primitive hematopoietic stem cells in BALB/cBy mice. Exp. Hematol., 27: 928-935.

9. Childs, R., et al. 2000. Regression of metastatic renal-cell carcinoma after nonmyeloablative allogeneic peripheral-blood stem-cell transplantation. N. Engl. J. Med., 343: 750-758.

10. Costa, G., et al. 2012. Origin of blood cells and HSC production in the embryo. Trends Immunol., 33:215223. 
11. Cutler, C., Antin, J.H. 2001. Peripheral blood stem cells for allogeneic transplantation: a review. Stem Cells, 19: 108-117.

12. Doetschman, T., et al. 1985. The in vitro development of blastocyst-derived embryonic stem cell lines: formation of visceral yolk sac, blood islands and myocardium. J. Embryol. Exp. Morph., 87: 27-45.

13. Domen, J., Weissman, I.L. 2000. Hematopoietic stem cells need two signals to prevent apoptosis; BCL-2 can provide one of these, $\mathrm{Kitl} / \mathrm{c}-\mathrm{Kit}$ signaling the other. J. Exp. Med., 192: 1707-1718.

14. Dzierak, E. 1999. Embryonic beginnings of definitive hematopoietic stem cells. Ann. N. Y. Acad. Sci., 872: 256-262.

15. Dzierzak, E., et al. 1998. Qualitative and quantitative aspects of hematopoietic cell development in the mammalian embryo. Immunol. Today, 19: 228-236.

16. Eilken, H.M., et al. 2009. Continuous single-cell imaging of blood generation from haemogenic endothelium. Nature, 457: 896-900.

17. Ema, H., et al. 2000. In vitro selfrenewal division of hematopoietic stem cells. J. Exp. Med., 192: 1281-1288.

18. Frame, J.M., et al. 2015. Definitive hematopoiesis in the yolk sac emerges from Wnt-responsive hemogenic endothelium independently of circulation and arterial identity. Stem Cells, doi: 10.1002/stem.: 2213.

19. Frame, J.M., et al. 2013. Erythromyeloid progenitors: 'definitive' hematopoiesis in the conceptus prior to the emergence of hematopoietic stem cells. Blood Cells Mol. Dis., 51:220 225.

20. Gallacher, L., et al. 2000. Identification of novel circulating human emnryonic blood stem cells. Blood, 96: 17401747.

21. Glimm, H., et al. 2000. Human Hematopoietic stem cells stimulated to proliferate in vitro lose engraftment potential during their $\mathrm{S} / \mathrm{G}(2) / \mathrm{M}$ transit and do not reenter $\mathrm{G}(0)$. Blood, 96: 4185-4193.

22. Gothot, A., et al. 1998. Cell cyclerelated changes in repopulating capacity of human mobilized peripheral blood $\mathrm{CD}_{34}{ }^{+}$cells in non-obese diabetic/severe combined immunedeficient mice. Blood, 92: 2641-2649.

23. Hole, N. 1999. Embryonic stem cellderived haematopoiesis. Cells Tissues Organs, 165: 181-189.

24. Jaffredo, T. et al. 1998. Intraaortic hemopoietic cells are derived from endothelial cells during ontogeny. Development, $\quad$ 125: 45754583.

25. Kaufman, D.S. et al. 1999. Directed differentiation of human embryonic stem cells into hematopoietic colony forming cells. Blood, 94(Supplement part 1): $34 \mathrm{a}$.

26. Lancrin, C. et al. 2012. GFI1 and GFI1B control the loss of endothelial identity of hemogenic endothelium during hematopoietic commitment. Blood, 120: 314-322.

27. Lancrin, C. et al. 2009. The haemangioblast generates haematopoietic cells through a haemogenic endothelium stage. Nature, 457: 892-895.

28. Lie-A-Ling, M. et al. 2014. RUNX1 positively regulates a cell adhesion and migration program in murine hemogenic endothelium prior to blood emergence. Blood, 124: e11-e20.

29. McGrath, K.E. et al. 2015. Distinct sources of hematopoietic progenitors emerge before HSCs and provide functional blood cells in the 
mammalian embryo. Cell Rep., 11: 1892-1904.

30. McSweeney, P.A., Storb, R. 1999. Mixed chimerism: preclinical studies and clinical applications. Biol. Blood Marrow Transplant, 5: 192-203.

31. Medvinsky, A.J., Dzierzak, E.A. 1996. Definitive hematopoiesis is autonomously initiated by the AGM region. Cell, 86: 897-906.

32. Müller, A.M., et al. 1994. Development of hematopoietic stem cell activity in the mouse embryo. Immunity, 1:291301.

33. Palis, J., et al. 1999. Development of erythroid and myeloid progenitors in the yolk sac and embryo proper of the mouse. Development, 126: 5073-5084.

34. Rybtsov, S., et al. 2011. Hierarchical organization and early hematopoietic specification of the developing HSC lineage in the AGM region. J. Exp. Med., 208: 1305-1315.

35. Sroczynska, P., et al. 2009. The differential activities of Runx 1 promoters define milestones during embryonic hematopoiesis. Blood, 114: 5279-5289.

36. Zovein, A.C., et al. 2008. Fate tracing reveals the endothelial origin of hematopoietic stem cells. Cell Stem Cell, 3: 625-636.

\section{How to cite this article:}

Pallavi Singh, Naman Naik and Lakhan L. Naik. 2016. Proliferatic Potential of Hematopoietic Stem Cells (HSC) and its Application in Human Diseases. Int.J.Curr.Res.Aca.Rev.4(3): 86-96. doi: http://dx.doi.org/10.20546/ijcrar.2016.403.010 